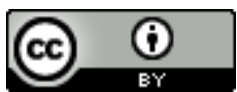

\title{
INOVAÇÃO, TIC E DOCÊNCIA: \\ PRÁtICAS E CONCEPÇõeS DE PROFESSORES EM UMA IES PRIVADA
}

\begin{tabular}{c}
\hline INNOVATION, ICT AND TEACHING: \\
PRACTICES AND CONCEPTIONS OF PROFESSIONALS IN A PRIVATE HEI \\
INNOVACIÓN, TIC Y DOCENCIA: \\
PRÁCTICAS Y CONCEPCIONES DE PROFESORES EN UNA IES PRIVADA
\end{tabular}

\section{Giselle Martins dos Santos Ferreira ${ }^{\mathrm{i}}$ Rejane Cunha Freitas Laélia Carmelita Portela Moreira}

\begin{abstract}
RESUMO: Os discursos hegemônicos sobre as Tecnologias de Informação e Comunicação (TIC) na Educação apresentam-nas como "ferramentas" essenciais à ampliação do acesso à Educação Superior (ES) em um contexto caracterizado pela globalização econômica e demandas por qualificação profissional continuada. Nessa perspectiva, a ES enfrenta o desafio de ampliar os números de matrículas adotando "soluções" técnicas para garantir a "qualidade" e a "relevância" de sua oferta. Há, entretanto, uma lacuna significativa entre tais discursos generalistas e a realidade. Este artigo constitui um recorte de um estudo de caso cujo objetivo geral foi examinar concepções e práticas docentes com as TIC na ES. Tomando como campo uma instituição de ES privada, coletaram-se dados por meio de questionários, observação participante e entrevistas. A presente discussão baseia-se em uma análise de conteúdo temática das 11 entrevistas conduzidas com docentes, adotando como fundamentação literatura da área da Docência Superior e textos críticos da Tecnologia Educacional. Os achados sugerem que, apesar das indicações de clara preocupação com a didática, concretizam-se formas de "inovação" com o uso de novos artefatos para apoiar práticas previamente conduzidas e focalizadas, basicamente, na "transmissão" de conhecimento. A situação explica-se, parcialmente, por contingências como falta de tempo, carência de formação específica e o "solucionismo" que caracteriza algumas ações e demandas institucionais relacionadas às TIC. Por outro lado, há indícios de práticas que sugerem enorme comprometimento com os alunos, o trabalho e a própria instituição. Assim, reitera-se a necessidade de estudos empíricos que desafiem discursos generalistas e, principalmente, a culpabilização do professor.
\end{abstract}

PALAVRAS-CHAVE: Educação superior. Tecnologia educacional. Inovação.

ABSTRACT: The hegemonic discourses on Information and Communication Technologies (ICT) in Education construe them as essential tools for widening access to Higher Education (HE) in a context characterized by economic globalization and demands for continued professional qualification. From this perspective, ES is confronted with the challenge of increasing enrollment numbers by adopting technical "solutions" to guarantee the "quality" and "relevance" of its provision. There is, however, a significant gap between such generalist discourses and reality. This article draws upon a case study that had the general aim of examining teaching conceptions and practices with ICT in HE. Data collection was conducted on a campus of a private Higher Education Institution (HEI), using questionnaires, participant observation and interviews. The discussion is based upon a thematic content analysis of the 11 interviews conducted with faculty members, adopting as basis literature on Higher Education and critical texts of Educational Technology. Findings suggest that, despite clear indications of concern with didactics, forms of "innovation" are materialized as uses of new artifacts to support previously conducted practices focused on knowledge transmission. The situation is partly explained by contingencies such as lack of time and specific training, as well as the "solutionism" that characterizes some

Submetido em: 27/09/2017 - Aceito em: 23/10/2017 - Publicado em: 03/10/2017.

\begin{tabular}{|l|c|c|c|c|c|} 
(C) Rev. Inter. Educ. Sup. & Campinas, SP & v.4 & n.1 & p.25-51 & jan./abr. 2018 \\
\hline
\end{tabular}


institutional actions and demands surrounding ICT. On the other hand, there are indications of practices that suggest enormous commitment to students, work and the institution itself. Thus, the need is reiterated for empirical studies that challenge generalist discourses and, especially, teacher blaming.

KEYWORDS: Higher education. Educational technology. Innovation.

RESUMEN: Los discursos hegemónicos sobre las Tecnologías de Información y Comunicación (TIC) en la Educación las presentan como "herramientas" esenciales para la ampliación del acceso a la Educación Superior (ES) en un contexto de globalización económica y demandas por cualificación profesional continuada. La ES necesita ampliar los números de matrículas adoptando "soluciones" técnicas para garantizar la "calidad" y la "relevancia" de su oferta. Hay, sin embargo, una laguna significativa entre tales discursos y la realidad. Este artículo constituye parte de un estudio de caso cuyo objetivo general fue examinar concepciones y prácticas docentes con las TIC en la ES. El campo fue una institución privada y datos fueron recolectados a través de cuestionarios, observación participante y entrevistas. La discusión se basa en un análisis de contenido temático de 11 entrevistas con docentes, adoptando como fundamentación literatura sobre la Docencia Superior y textos críticos de la Tecnología Educativa. Los resultados sugieren que, no obstante las indicaciones de preocupación con la didáctica, se concretan formas de "innovación" con el uso de nuevos artefactos para apoyar prácticas previamente conducidas y focalizadas, básicamente, en la "transmisión" de conocimiento. Esto se explica, parcialmente, por falta de tiempo, carencia de formación específica y el "solucionismo" que caracteriza algunas acciones y demandas institucionales relacionadas a las TIC. Tambiém hay indicios de prácticas que sugieren un enorme compromiso con los alumnos, el trabajo y la institución. Así, se reitera la necesidad de estudios empíricos que desafien discursos generalistas y, principalmente, la culpabilización del profesor.

PALABRAS CLAVE: Educación superior. Tecnología educativa. Innovación.

\section{INTRODUÇÃO}

O papel do conhecimento e da informação como determinantes do desenvolvimento econômico, social e individual tem sido enfaticamente ressaltado em discursos disseminados por agências globais tais como o Banco Mundial, a Organização de Cooperação e Desenvolvimento Econômicos (OCDE) e a UNESCO. Em particular, os discursos em torno da "sociedade do conhecimento", conforme sugere Kazamias (2012), enfatizam, além do grande desenvolvimento das Tecnologias de Informação e Comunicação (TIC), a ascensão de uma "sociedade em rede" (CASTELLS, 2000), na qual o conhecimento é mercadoria negociável e os modos de organização da vida e do trabalho são orientados por uma racionalidade tecnocientífica. Consolida-se um imaginário sustentado na ideia de que as atividades produtivas das quais depende o desenvolvimento das nações são função da ciência e tecnologia avançadas. Nessa perspectiva, boa parte das estratégias de desenvolvimento de um país deve sustentar-se na escolarização crescente dos seus cidadãos, em sua qualificação continuada, na expansão da pesquisa científica e tecnológica e, em particular, na "inovação".

A noção de "inovação" tem sido defendida como base para o enfrentamento do desafio posto à Educação Superior (ES) em contexto mundial: atender ao crescente aumento no número de matrículas. Segundo Altbach, Reisberg e Rumbley (2009), o aumento da demanda pela ES explica-se, em parte, como uma consequência da economia globalizada, da demanda por 
aprendizagem ao longo da vida e da necessidade de trabalhadores com formação superior. Sob essa ótica, a ideia da massificação é inevitável e oferece possibilidades de maior mobilidade social para um segmento crescente da população, bem como novos padrões de financiamento e sistemas de ES, cada vez mais diversificados. Concretizam-se, assim, as demandas impostas pela economia do conhecimento.

Entretanto, a noção de "inovação" é polissêmica, conforme assinalado por Masetto (2004), que elenca diversos imperativos postos à Educação Superior contemporânea e que, teoricamente, justificam as demandas por "inovação". Concepções correntes do termo são fortemente marcadas com características tecnicistas, pois carregam consigo o peso da competição na "sociedade do conhecimento", do mercado, do mínimo custo e da máxima eficiência. Em particular, quando trazida para o campo da Educação pela vertente instrucionista da Tecnologia Educacional (FERSTER, 2014), cuja "ideia-chave é o aumento da 'eficácia' da aprendizagem" concretizada em economias de tempo, de recursos e de esforços, a "inovação" tende a ser pensada quase que exclusivamente em termos da presença, em contextos educacionais, de artefatos digitais (ROSADO; FERREIRA; CARVALHO, 2017, p. 237). Porém, como sugere Cunha (2012, p. 128), a inovação no campo educativo "é resultado de tensões e não meramente a inserção de novidades técnicas e tecnológicas, como dispositivos modernizantes". Nesse sentido, uma concepção emancipatória de inovação é construída por meio de resistências e experiências acadêmicas alternativas, no sentido de construir um espaço de contradições, de criação e de utopia.

No Brasil, tem havido investimentos governamentais (e privados) significativos em laboratórios e bibliotecas, com aquisição de equipamentos, softwares e acesso à Internet com banda larga, com o propósito de contribuir para a ampliação do acesso à educação. A expansão da infraestrutura tecnológica das Instituições de Ensino Superior (IES) privadas, em especial, tende a ser utilizada para construir sua imagem como promotoras de "qualidade" e de "inovação". No entanto, o avanço tecnológico "não foi articulado com mudanças estruturais no processo de ensino, nas propostas curriculares e na formação dos professores universitários para a nova realidade educacional", sugere Kenski (2012, p. 116). Segundo a autora, boa parte dos professores universitários utilizam as TIC em outros contextos e contribuem, inclusive, para a cultura da inovação na pesquisa, mas a maioria não usa TIC como recurso pedagógico.

Este artigo constitui um recorte de um estudo de caso que teve por objetivo examinar concepções e práticas docentes com as TIC na Educação Superior. Tomando como campo uma IES privada, foram coletados dados por meio de questionários, observação participante e entrevistas, os quais foram analisados à luz de literatura da área da Docência Superior e textos críticos da Tecnologia Educacional. A fundamentação teórica é discutida na próxima seção, que é seguida de uma apresentação sucinta da metodologia da pesquisa. A discussão dos

n.1

p.25-51
jan./abr. 2018 
achados, apresentada em duas seções, baseia-se em uma análise de conteúdo temática das 11 entrevistas semiestruturadas conduzidas com docentes da instituição.

\section{EDUCAÇÃO SUPERIOR E AS TIC}

No Brasil, desde o início dos anos 1970, o crescimento da ES foi impulsionado pela expansão de uma sociedade mais urbana e mais industrializada; assim, "[...] para um contingente cada vez maior da população, a formação superior passava a fazer parte de seus projetos de realização pessoal e de ascensão social" (SAMPAIO, 2011, p. 29). Outro marco na expansão do ensino superior privado no país foi o Decreto 2.306, de 19 de agosto de 1997, que abriu a possibilidade de que entidades mantenedoras de instituições de ensino superior pudessem assumir "[...] qualquer das formas admitidas em direito, de natureza civil ou comercial" (BRASIL, 1997, s. p.). Assim, como em diversos países, nacionalmente, os investimentos privados em educação superior cresceram, inclusive, em taxas maiores, na média, que os investimentos públicos (OCDE, 2012).

Decorre, portanto, a preocupação com a massificação e o financiamento privado na educação, bem como as dúvidas sobre a possibilidade de equilibrar uma gestão dos sistemas de educação superior voltada para o lucro e o compromisso com qualidade acadêmica. Apesar do consenso quanto à relevância da qualidade, a própria discussão sobre o que é "qualidade" na ES já provoca, por si só, polêmica, e parece longe de consenso, pois diferentes perspectivas (acadêmicas versus empresariais) estão presentes nos estudos sobre esse segmento educacional (HARVEY; WILLIAMS, 2010; FERREIRA; MOREIRA, 2014). Ainda assim, algumas questões prementes persistem: como compatibilizar amplo acesso e qualidade de formação e como concretizar o ideal de uma educação superior como um direito cidadão quando o financiamento público é restrito.

Nesse contexto, em meio a ações institucionais de inserção de TIC de forma top-down, dissemina-se a ideia de que os professores são resistentes a mudanças. Porém, já em 2001, Cuban (2001) argumentava que esses docentes não tendem a ser tecnófobos, ou seja, não são fundamentalmente contra o uso de tecnologias. Na realidade, no exercício da docência, eles se veem pressionados de formas diversas, pois lidam com alunos que querem ensino de "qualidade", empresários que querem pesquisas aplicadas, pais que querem diplomas de prestígio para (supostamente) garantir altos salários para seus filhos. Diferentes atores exigem que os professores usem a melhor tecnologia para ensinar seus alunos da forma mais eficiente.

Entretanto, a crescente demanda pelo uso de artefatos digitais ignora, frequentemente, as realidades do "chão da sala de aula", amplamente mascaradas por discursos generalistas de

\begin{tabular}{l|l|l|l|l|l}
\hline (C) Rev. Inter. Educ. Sup. & Campinas, SP & v.4 & n.1 & p.25-51 & jan./abr. 2018 \\
\hline
\end{tabular}


caráter prescritivo, que obscurecem questões sociais e políticas localizadas. Dissemina-se amplamente aquilo que se pensa ser possível fazer com as tecnologias, “[...] na literatura do gênero 'futurologia', que tende a apresentar visões do que pode ser como se fossem descrições do que ê" (FERREIRA; ROSADO; CARVALHO, 2017, p. 10; grifo original dos autores). Enquanto as TIC oferecem múltiplas possibilidades de uso e, portanto, podem ter uma variedade de contribuições aos processos de ensino-aprendizagem, podem não ocasionar, na prática, mudança alguma. No entanto, como sugere Selwyn (2017), “[...] a possibilidade da tecnologia não conduzir à aprendizagem ou a outros ganhos educacionais é raramente assunto para consideração" (SELWYN, 2017, p. 98). Infelizmente, as inserções de tecnologia na educação baseiam-se frequentemente em estratégias do "solucionismo", noção proposta por Evgeny Morozov (2013 apud SELWYN, 2017, p. 92) que expressa a ideia de tecnologias propostas como "solução" de "problemas" mal formulados, configurando, na prática, situações de "soluções" em busca de "problemas".

Parece mais produtivo que o debate se desenvolva em torno de uma melhor compreensão e reconhecimento das implicações das TIC na ES como um "conjunto de continuidades", resultantes de contextos histórica e institucionalmente situados institucionalmente, "em vez de um conjunto de descontinuidades radicais" (SELWYN, 2011, p. 53). Assim, impõe-se a necessidade de identificar significações, esmiuçar tendências e contrapô-las com empiria e críticas fundamentadas. Além disso, questões bem formuladas podem investigar os limites das tecnologias na educação, explorar os tipos de usos dos artefatos digitais, as capacidades dos estudantes em utilizar essas tecnologias e os contextos acadêmicos que colocam as TIC como símbolo de "inovação" na Educação ou as concepções dos professores inseridos nesses contextos, como é o caso do estudo no qual o presente artigo está baseado.

\section{METODOLOGIA}

As seguintes questões nortearam o estudo:

- De que formas os docentes concebem a integração de recursos das TIC em suas práticas de ensino?

- Quais as concepções, atitudes e dificuldades dos professores em relação ao uso das TIC em sala de aula?

- Quais concepções de "inovação" emergem do campo de visão dos professores?

A coleta de dados combinou procedimentos quantitativos e qualitativos para registrar as concepções dos docentes sobre suas práticas de ensino e o uso das TIC em sala de aula. Assim, foram utilizados questionários, entrevistas semiestruturadas e observação participante. A coleta de dados foi realizada entre setembro de 2013 e fevereiro de 2015. Os questionários 
(total 70) foram estatisticamente analisados, de modo a possibilitar a identificação do perfil dos docentes em relação à sua formação e experiência profissional, possibilitando, também, uma primeira aproximação do uso de TIC para fins diversos. Este artigo, porém, trata, primordialmente, dos resultados da análise das entrevistas com 11 dos professores que participaram desta etapa da investigação.

Nas entrevistas, os professores foram convidados a falar sobre seu fazer pedagógico, como planejavam suas aulas e como as concretizavam em seu cotidiano. Em relação ao uso das TIC em sala, os entrevistados foram questionados quanto às estratégias mais utilizadas em sala, estando elas associadas ao uso das TIC, ou não. Foram discutidas possíveis vantagens e desvantagens do uso das tecnologias em sala de aula, bem como concepções acerca de práticas "inovadoras" no ensino, inclusive, com descrição de exemplos. As entrevistas foram gravadas e transcritas com apoio do software Express Scribe Transcription, próprio para escuta e transcrição. Bardin (1977) e Cohen, Manion e Morrison (2007) foram as referências utilizadas para o processo de análise do conteúdo, e o software NVivo foi usado para apoiar esse processo.

\section{Sobre o campo da pesquisa}

O estudo de caso foi realizado em uma IES privada com fins lucrativos, que tem presença em várias cidades do país, e cujas estratégias de marketing, como em outras de caráter privado, representam, destacadamente, "qualidade" e "inovação", como demandas para as IES contemporâneas. O campus onde a pesquisa se desenvolveu oferece cursos diversificados de graduação (tradicional e tecnológica) e de pós-graduação lato-sensu, nas modalidades presencial, a distância e semipresencial nas áreas das Ciências Sociais, Ciências da Saúde Aplicadas, Ciências Humanas, Engenharias e Ciências Exatas, dentre outras com menor representação.

A instituição possui, para cada curso de graduação ofertado, uma organização curricular unificada, com currículos, planos de ensino, material didático digital (que recentemente substituiu o impresso), planos de aula e modelo de avaliações, de uma mesma disciplina, integrados em um "modelo de ensino" institucional. Para a criação (e reformulação) desse material existe a possibilidade (pelo menos em teoria) de discussão coletiva entre os docentes dos cursos em diferentes campi da instituição, através de uma ferramenta de gestão do conhecimento, mas a produção dos recursos é gerida (e quase sempre conduzida, na prática) de forma centralizada, constituindo-se, assim, o "modelo de ensino".

Os alunos e os professores têm acesso a capítulos de livros indicados como material didático para as disciplinas, bem como a uma diversidade de livros por meio de uma biblioteca virtual e bibliotecas físicas. Os professores também têm acesso a sistemas para disponibilização de 
notas de aula, exercício, trabalhos, para lançamento de frequências e notas. Os alunos, por sua vez, além dos materiais postados por seus professores, acessam informações sobre seu histórico escolar, matrículas, cursos de extensão, atividades complementares, dentre outras. Integra, também, o conjunto de sistemas institucionais um $\mathrm{LMS}^{2}$ utilizado como repositório de materiais dos professores e como espaço para postagem de trabalhos pelos alunos. Nacionalmente, os professores precisam utilizar esse conjunto de sistemas em seu cotidiano. Outros sistemas institucionais, a exemplo da rede social corporativa e dos serviços da Intranet, possuem uma orientação de uso mais flexível. Alunos e professores de cursos de graduação específicos recebem tablets.

O termo "inovação" figura com destaque nos documentos estratégicos da instituição, predominantemente no sentido de implantação de produtos (e serviços) novos ou melhorados, que visam à criação e à oferta de um "ensino universitário de qualidade", bem como à manutenção de uma "vantagem competitiva" atribuída a seus egressos. Dentre esses produtos e serviços, destacam-se uma incubadora de startups e uma unidade dedicada ao desenvolvimento e implantação de tecnologias educacionais que incluem jogos educativos, um dispositivo integrado que substitui o conjunto quadro branco, computador e Datashow, que supostamente permite maior interação pela conectividade com os dispositivos dos alunos, e um ambiente de realidade virtual com a possibilidade de manipulação de objetos 3D a distância.

Tais características e ações sustentam o argumento das campanhas de marketing que constroem a imagem de uma instituição que "inova", a partir de materiais de propaganda fortemente baseados em slogans em torno de cursos que possuem "qualidade diferenciada", "preços competitivos", "foco na formação profissional" dos alunos e, como principal público alvo, os "trabalhadores de classes média e média-baixa", ainda que o público seja diversificado e inclua, principalmente nos cursos diurnos, jovens. Crucialmente, as demandas institucionais por "inovação" refletem-se no cotidiano acadêmico e, certamente, contribuem para forjar as concepções expressas pelos docentes acerca do planejamento e melhoria das práticas de ensino, uso (ou não) das TIC, compartilhamento de recursos, bem como desenvolvimento profissional.

\section{Sobre os participantes}

De modo a manter o anonimato dos participantes, são utilizados os pseudônimos mostrados no Quadro 1, que inclui informações sobre formação, titulação e área de concentração das

\footnotetext{
2 Acrônimo do inglês Learning Management System, Sistema de Gestão da Aprendizagem. De forma geral, constituem plataformas que integram funcionalidades de Ambientes Virtuais de Aprendizagem (AVA) e sistemas de administração escolar. $\mathrm{O}$ acrônimo do termo original é utilizado pelos participantes da pesquisa, bem como na literatura nacional da área.
} 
disciplinas que lecionam.

Quadro 1. Formação, titulação e área de concentração das disciplinas lecionadas pelos professores entrevistados

\begin{tabular}{|c|l|}
\hline Pseudônimo & \multicolumn{1}{|c|}{ Formação, titulação e área de concentração das disciplinas que leciona } \\
\hline Artur & Graduado em Direito, mestre, também leciona disciplinas relacionadas às Ciências Jurídicas. \\
\hline Cecília & $\begin{array}{l}\text { Graduada em Administração de Empresas, doutora, leciona disciplinas relacionadas à } \\
\text { Gestão e Negócios. }\end{array}$ \\
\hline César & $\begin{array}{l}\text { Graduado em Arquitetura, mestre, leciona disciplinas relacionadas à na área da Ciência da } \\
\text { Computação e também em curso de Arquitetura. }\end{array}$ \\
\hline Dário & Graduado em Engenharia, mestre, leciona disciplinas relacionadas à Gestão e Negócios. \\
\hline Eduardo & $\begin{array}{l}\text { Graduado em curso tecnológico na área da Ciência da Computação, especialista, leciona } \\
\text { disciplinas também em cursos na área da Ciência da Computação. }\end{array}$ \\
\hline Francisco & $\begin{array}{l}\text { Graduado em Engenharia, doutor, leciona disciplinas relacionadas às Tecnologias da } \\
\text { Informação. }\end{array}$ \\
\hline Lígia & $\begin{array}{l}\text { Graduada em curso tecnológico na área da Ciência da Computação, especialista, leciona } \\
\text { disciplinas também em cursos na área da Ciência da Computação. }\end{array}$ \\
\hline Lúcia & $\begin{array}{l}\text { Graduada em Biologia (licenciatura), pós-doutora, leciona disciplinas relacionadas à } \\
\text { Ciências da Saúde. }\end{array}$ \\
\hline Raquel & $\begin{array}{l}\text { Graduada em Letras (licenciatura), mestre, leciona disciplinas, principalmente, relacionadas } \\
\text { às Ciências Jurídicas. }\end{array}$ \\
\hline Rodrigo & Graduado em Direito, mestre, também leciona disciplinas relacionadas às Ciências Jurídicas. \\
\hline Virgínia & $\begin{array}{l}\text { Graduada em Pedagogia e em Administração de Empresas, mestre, leciona disciplinas } \\
\text { relacionadas à Gestão e Negócios. }\end{array}$ \\
\hline
\end{tabular}

Fonte: pesquisa de campo

Os professores participantes atuavam na instituição de formas diversificadas: além da docência presencial e on-line, eram também coordenadores de curso, exercendo cargos acadêmicos e administrativos ou, ainda, conduzindo atividades de pesquisa. Assim, caracterizam-se diferentes tipos de vínculos com a instituição, incluindo professor contratado como horista, professor em tempo parcial e professor em tempo integral, alguns com dedicação exclusiva à instituição.

\section{COM A PALAVRA, OS PROFESSORES}

A discussão dos achados da análise, apresentada a seguir, está organizada em três linha temáticas: "práticas", "artefatos" e "concepções / preconcepções".

\section{Práticas}

Nos relatos sobre métodos, estratégias de aulas e ações de planejamento, os principais aspectos destacados são o "conteúdo", os objetivos e o tempo empreendido nesse processo. A fala a seguir expressa, de forma contundente, o papel de centralidade atribuído ao "conteúdo": 
Francisco: Quando eu peguei a $<$ Disciplina $10>$, a primeira coisa que eu fiz foi olhar realmente o conteúdo.

A preocupação com o "conteúdo" a ser ministrado está associada a uma identificação da ação docente com as noções de "dominar" e "transmitir com segurança", conforme sugere o excerto abaixo:

Artur: Então, quando vem uma disciplina, a primeira preocupação é o conteúdo, é me apoderar e dominar esse conteúdo de forma a transmitir com segurança para os meus alunos, responder aos questionamentos. Então, [...] o que vem primeiro é o conteúdo. (Ênfase das autoras)

Uma estratégia adotada pelos professores é procurar colegas que já tenham ministrado a mesma disciplina:

César: Consulto primeiro o professor mais experiente no assunto; procuro o coordenador e digo: 'Olha qual é...' Então, aí eu deixo que o professor fale à vontade o que ele tem a dizer. [...] E aí, eu assimilei isso daí e depois fui procurando perguntar para ele quais eram as referências bibliográficas que ele tinha e se tinha material de aula disponível na Xerox para eu poder pegar e fazer uma leitura pra me atualizar, basicamente é isso que eu procuro.

Dário: Eu comecei, a primeira coisa que faço é perguntar quem foi o professor que deu a disciplina, pra eu poder pegar o material dele, justamente pra poder me ajudar também.

No centro desses relatos, situam-se referências a slides, que, segundo os professores, não somente possibilitam roteirizar, resumir, ilustrar, ajudando-os na organização das suas próprias falas, mas, também, constituem o produto final do planejamento: deles se parte para a prática. Assim, planejar, para os professores, significa colocar o "conteúdo" da aula em slides a serem utilizados, primordialmente, em aulas expositivas:

Francisco: Minhas aulas, normalmente, são expositivas.

Arthur: Então, eи evito escrever, primeiro porque eu quero ganhar tempo e falando eu acho que sou mais rápido, eu digo pessoal nosso ponto de hoje é isso, nós vamos concentrar a nossa discussão hoje em cima disso.

No conjunto dos dados das entrevistas, a explanação oral aparece como a estratégia mais usada em sala. Nas falas acima, Francisco assume sua preferência sem explicitar motivos, enquanto Artur revela acreditar que "ganha tempo", ainda que não deixe claro se a "discussão" em questão inclui os alunos. Por outro lado, os dados incluem indícios de tentativas de diminuir o uso dessa estratégia a partir de feedback dos alunos, às vezes, silencioso: 
Lígia: [...] eu primeiro falo um pouco, aí depois vejo que já está cansando [...].

Em contraste com a exposição oral, situações que objetivam estimular o debate com os alunos por meio de associações dos "conteúdos" a situações da vida real também figuram nas falas docentes. De fato, alguns deles defendem tais associações de modo enfático, conforme ilustram os extratos a seguir:

Lúcia: Você tem esse exemplo aqui na Fisiologia, como seria... como ficaria o coração? Também trago vários exemplos de Patologia para o pessoal da Curso. E eu tento trazer para a realidade deles para não ficar uma coisa teórica.

Dário: Eu procuro colocar exemplos e situações que elas vivenciam e como eu coloco isso, eles ficam: "Ah, professor, eu vi isso na empresa!". Aprendem muito mais fácil. Quando você começa a trabalhar com o princípio da analogia, com o princípio da similaridade.

O extrato seguinte descreve uma estratégia que integra exposição, mas contempla, também, o debate e troca de ideias na sala, bem como, ao final, a reflexão construída em conjunto:

César: Eu gosto de dar é a (aula) expositiva, discursiva e com reflexão no final. É aquela que a gente apresentou o conteúdo, eu dou o insumo daquilo ali, as referências, as imagens, os modelos, os fatos e aí, em cima disso, a gente vai estabelecendo juntos um discurso, para, no final, chegar a uma reflexão daquela aula de determinado assunto.

Tais adaptações da exposição mais tradicional sugerem uma preocupação dos professores com reduzir o tempo de explanação, para que possam propor atividades que demandam maior engajamento dos alunos:

Cecília: Às vezes, eu dou a aulinha tradicional e explico [...]; às vezes, faço texto, procuro variar esse estilo.

Rodrigo: Eu vou ministrar um conteúdo da maneira tradicional, aí eu peço para o aluno quando a gente vai avançando no conteúdo, pessoal façam os cases número tais e tais.

Os cases (também conhecidos como "casos concretos") mencionados acima consistem em descrições de exemplos de aplicação prática de determinada teoria. Trata-se de um tipo de recurso disponibilizado pela instituição como proposta para "ajudar os alunos na associação entre teoria e prática", e cujo uso já se tornou compulsório, na prática. A fala seguinte ilustra uma situação de uso apoiado pelo trabalho em grupo:

Rodrigo: [...] como é que eu costumo fazer: eu trago o caso pra (sic) gente analisar, separo em pequenos grupos, deixo eles discutirem um tempinho em grupos, depois eu trago a discussão para o grupo geral. Às vezes, eu peço para um pequeno grupo dizer o que eles concluíram e outro falar de outro caso, é o que a gente faz. 
Nos extratos seguintes, Francisco comenta sobre o trabalho com projetos, e Rodrigo se refere à realização em sala de um "júri simulado". Essas estratégias parecem bem características das respectivas áreas de formação dos entrevistados (Engenharia e Direito), e, talvez, representem estratégias que conheceram e vivenciaram quando alunos:

Francisco: [...], mas, vamos supor, um projeto que significa assim, que... eu acho que é interessante porque elenca, liga todos os conhecimentos que eles receberam, mais ou menos até a Unidade $1>$, apesar de continuar um pouco depois, < Unidade $2>$, mas eles fazem como se fosse a síntese do negócio, tá entendendo?

Rodrigo: Já procurei também fazer uma coisa que eu acho que eles até gostam, aquela coisa da disputa que é, por exemplo, colocar uma situação, que com o Direito dá para fazer muito bem... tipo assim, um vai ter que defender uma visão, um lado, outro vai ter que defender a outra, mais ou menos um julgamento simulado, ou algo do tipo e aí colocar eles no embate. Eles acham bacana, até participam bastante.

A utilização de recursos audiovisuais em sala de aula também aparece nos dados, mas sem consenso sobre a melhor forma de integrá-los:

Virgínia: Eu peguei duas aulas, parti o filme, e a gente levou pipoca e tudo, aí eu botei um roteiro de pergunta, direcionado ao conteúdo que eles captassem do filme. (Êfase das autoras)

Rodrigo: Às vezes o professor, até assim, querendo diversificar, passava um filme inteiro, aí você assiste o filme inteiro, é a aula todinha para assistir o filme. Às vezes, duas horas para assistir o filme e aí depois você vai querer discutir alguma coisa do filme, é meio complicado. Eu acho que você focar, estou falando desse assunto, o filme aborda esse assunto, nesse ponto, mesmo que eu tenha que contextualizar para quem não assistiu, o filme fala disso e disso.

Algumas práticas descritas destacam-se por seu teor de experimentação e pela disponibilidade dos professores em adaptar-se às necessidades que percebem dos alunos:

César: [...] a gente vai falar sobre a influência de determinadas tatuagens no personagem e na cultura das pessoas, aí a gente pega imagens, referências, que tem a ver com o universo dos alunos, pra fazer esse discurso... ai pronto: "Agora você vai criar um personagem".

Lígia: Eu acho que se realmente ficar só $100 \%$ é a questão do exagero, a mesma coisa se eu fizer o inverso, $100 \%$ só teórico, só conceito, também não resolve. Agora eu vou só escrever no quadro, não, tem que mesclar quadro, slide, simulador, máquina virtual, momentos de uma avaliação em sala, um exercício em sala.

Os dados indicam que o trabalho cotidiano em sala de aula frequentemente proporciona aos professores o desenvolvimento de certos questionamentos, por exemplo, entre abordar "conteúdos" de forma mais generalista ou aprofundada, entre focalizar em questões 
conceituais ou fomentar sua articulação com a prática, entre minimizar ou explorar momentos nos quais as vozes dos alunos sejam ouvidas. De fato, os depoimentos sugerem que algumas questões parecem ter resultado de reflexão sobre a prática, bem como de uma proposta de flexibilização dos níveis de exigência conforme a maturidade percebida das turmas. Contudo, esses depoimentos contêm, também, indícios de processos que encorajam a transformação de docentes em "instrutores", questão delicada e tratada de forma reticente pelos entrevistados, mas que emerge em suas falas a respeito de artefatos tecnológicos, conforme discutido a seguir.

\section{Artefatos}

A criação de slides, já discutida como prática de todos os professores entrevistados, é feita, via de regra, com o software PowerPoint. A relação entre o software, os slides e as práticas docentes é expressa de maneira contundente nos extratos a seguir:

César: Eu pelo menos, sou totalmente refém do PowerPoint.

Dário: Obviamente, que a maior parte de minhas aulas, certo, são em cima de materiais, são em cima de projeção, slides tudo mais. Realmente, eu não consigo dar uma aula sem um projetor multimídia, um PowerPoint.

Outro recurso das TIC utilizado pelos entrevistados são os vídeos, principalmente aqueles disponibilizados pelo site de streaming YouTube:

César: [...] pra mim, o YouTube é um grande, grande parceiro. É impressionante, você encontra de tudo, tranquilo.

Eduardo: [...] e eu tenho muito comigo essa história de videoaulas a posteriori e, normalmente, eu uso esse tipo de coisa nas minhas aulas.

O tipo de uso descrito é caracteristicamente norteado por uma abordagem de transmissão: o professor "passa" o vídeo para o aluno assistir ou recomenda como portal de acesso a videoaulas. Não são citados outros usos possíveis, como aqueles associados a funcionalidades de criação e edição dos vídeos oferecidas nesse mesmo site.

Os dados sugerem usos diferenciados de artefatos tecnológicos de acordo com a área de conhecimento em questão. Os professores de cursos da área da Computação, em particular, utilizam tais recursos como fim, como tópicos de aula, por exemplo, ferramentas de modelagem para ensinar certas etapas da criação de softwares ou de bancos de dados. De fato, os usos das TIC por docentes da Computação são, caracteristicamente, instrumentais, e referem-se a demandas profissionais específicas, que acabam se sobrepondo às questões dos usos dos softwares para fins pedagógicos: 
César: Os softwares que uso nas disciplinas totalmente práticas, eminentemente, o AutoCad, que é o programa de desenho gráfico, para $\langle$ Curso B $>$. No $\langle$ Curso C $>$, o pacote Adobe de design gráfico, Adobe Photoshop, Flash, os programas de manipulação.

Um outro exemplo de uso diferenciado dos recursos tecnológicos em sala refere-se a simulações. $\mathrm{O}$ extrato a seguir sugere uma combinação de uso instrumental (no exemplo, máquinas virtuais e analisadores de pacotes) e o uso pedagógico:

Lígia: No caso dos softwares que eles usam, tanto de diagramação de redes (Visio), quanto de simulador, analisador de pacotes (Wireshark) e as máquinas virtuais (Virtual Box-Oracle), para a questão dos servidores.

A fala a seguir sugere uma total dependência de recursos multimídia, pela possibilidade que oferecem de fornecer certo dinamismo e flexibilidade às aulas. O professor é arquiteto, mas leciona tanto em cursos de Arquitetura, como em cursos da área da Computação. Nesse contexto, especificamente, os recursos das TIC parecem ser não apenas facilitadores do fazer pedagógico, mas, de fato, determinantes:

César: E aí é sempre partindo desse princípio [aula expositiva com participação e reflexão com o aluno], eu tenho uma massa de conteúdo, meus PowerPoints, eles não têm ordem, necessária, específica, tem só os volumes. Volumes de conteúdo da aula 1, tem uma quantidade imagética de conteúdo e dados, tá semiestruturada ... Eu só trabalho com recurso áudio visual, vídeo, o que eu puder botar de coisas animadas, com som, eu coloco nos trabalhos... Todos já estão embarcados na máquina, no desktop, o aluno vai acessar, têm recursos visuais que emulam a tela dele... E eu tô sempre com meu $4 G$ ligado, que sempre, sempre, sempre tem uma diferença enorme, que se eu não tiver acesso a essa imagem, aí a gente pode perder o conteúdo, e aí eu já acesso direto [...].

Os professores que não lecionam disciplinas na área da Computação, por outro lado, parecem utilizar, além do PowerPoint, TIC para a obtenção de informações ou recursos de apoio: o motor de busca do Google aparece repetidamente em seus relatos, bem como buscas diretas em sites especializados, já conhecidos. Constitui-se, assim, uma concretização básica do conceito BYOD (Bring Your Own Device), caracterizado pelo uso em sala de dispositivos dos próprios alunos. A integração de artefatos como meio de acesso a recursos complementares, fora de sala de aula, também figura nos dados, mas uso de artefatos em sala parece ser função da expertise ou fluência do docente com as tecnologias. Assim, enquanto tal aspecto não se apresente como um desafio nas falas dos professores da área da Computação, seus colegas tendem a qualificar os usos que fazem de tecnologias como "não especializado":

Artur: Não me considero fluente tecnológico, de jeito nenhum, o básico eu manuseio sem o menor problema, o básico [...].

Raquel: Eu uso smartphone, iPad, computador pessoal, eu uso... não gosto muito,

\begin{tabular}{l|l} 
Campinas, SP & v.4
\end{tabular}

n.1

p.25-51
jan./abr. 2018 
por exemplo, de mexer em redes sociais, não sou do tipo que fica ali vidrada, direto. Mas eu gosto de fazer leituras, gosto de consultar sites, gosto de ler, meus jornais são todos pela Internet. Eu já faça uso de livros digitais, eu tenho também é o tablet, o leitor digital, o Kobo, vou até comprar outro da Kindle, também, porque às vezes tem um livro que quero [...].

Ainda que a autora da última fala acima não pareça saber distinguir os artefatos com precisão, um interesse pelos artefatos parece claro. As potenciais vantagens oferecidas pela portabilidade que caracteriza os artefatos móveis (smartphones e tablets, especialmente), implícita no extrato acima, fica clara a seguir:

Lúcia: [...] eu uso o iPad, tenho computador, agora estou passando as coisas mais para o iPad, porque é mais fácil de carregar [...].

Dentre os professores que se apresentam como "não especializados", alguns admitem buscar ajuda de outras pessoas: "um marido que é analista de sistemas", "amigos da área da informática" e "os próprios alunos". Porém, para além de questões instrumentais, relativas ao manuseio dos artefatos, há outros aspectos em jogo:

Virgínia: Então, você tem aquele professor mais antigo, tradicional, que ele tem vontade de aprender, reaprender a trabalhar com os novos recursos que tem em sala de aula e têm outros que, realmente têm muita dificuldade, têm medo da tecnologia, do novo, não deixa o professor... coisa simples ele não consegue.

Francisco: A gente já usa, já faz parte do dia a dia, mas... que é a própria Internet, são as tecnologias da Internet, mas como é que você vai transpor pra aula... que não são tecnologias difíceis de serem aplicadas, mas de todo jeito tem que preparar material e tudo mais [...].

Cecília: Não usei aplicativo não... até porque, eu acho que eu precisava muito fazer... era isso que eu queria que tivessem cursos que a gente pudesse fazer para conhecer, estou aberta... Eu queria que tivesse um debate pra gente criar novas coisas, sabe? De práticas, de linguagem, de coisas que apareceu, de jogos [...].

Os achados obtidos dos questionários sugerem que o corpo docente da instituição, em geral, utiliza com frequência as TIC em suas vidas fora da sala de aula (FREITAS; FERREIRA, 2016). Porém, os depoimentos colhidos nas entrevistas sugerem que os usos que fazem em sala são relativamente limitados. De fato, as falas apresentadas sugerem que a presença de artefatos digitais na sala agrava um problema que já existia antes: a criação de práticas diversificadas com a utilização de artefatos. Para além de questões de uso instrumental, um problema significativo é a abordagem pedagógica. Os dados indicam uma forte tendência à integração de artefatos para desempenhar funções e conduzir práticas previamente existentes: a "transmissão de conteúdo" por meio da aula expositiva apoiada por imagens pode ser feita com o uso do Datashow, do retroprojetor, do quadro ou da videoaula. 
Crucialmente, existe um direcionamento institucional para a integração, no ensino presencial, de diversos sistemas digitais originalmente desenvolvidos para os cursos a Distância. A instituição não apenas disponibiliza, mas vem, de fato, gradativamente tornando compulsório o uso desses sistemas para diversas atividades docentes. Em particular, o LMS institucional, anteriormente dedicado aos cursos oferecidos a distância, tem tido seu uso paulatinamente integrado às demandas do ensino presencial de diversas formas:

Cecília: Eu tenho turma que tem o tablet, usa assim pra acompanhar, né? Acompanhar a matéria, porque tem os slides, os slides estão no LMS institucional $[\ldots]$.

Rodrigo: Os alunos acessam o LMS institucional, postam no sistema as respostas dos casos.

Artur: Em sala de aula eu utilizo o LMS institucional, eu utilizo com muita frequência $[\ldots]$.

Francisco: Uso também o LMS institucional, porque agora a gente tem as atividades estruturadas, aí tudo está sendo feita através dele.

As falas revelam que, além de um espaço para a disponibilização de recursos complementares, o LMS tornou-se obrigatório no "modelo de ensino" da instituição, que, além de propor um projeto pedagógico e ementas de disciplinas específicas, define, em muitos casos, os próprios "conteúdos" a serem "trabalhados" nas aulas. O professor, nesse contexto, cada vez mais se aproxima de um "instrutor" que conduz uma espécie de mediação entre os aprendizes e os recursos de aprendizagem centralmente selecionados por outros atores na instituição.

Ainda assim, o uso desses recursos em sala de aula depende da infraestrutura oferecida localmente, cujas condições podem variar a ponto de forçar o próprio docente a investir em equipamentos:

César: [...] eu, independentemente da instituição dar infraestrutura, dar tudo bem direitinho, mas eu tenho um mini Datashow, tenho caixa de som, tenho cabo, tenho tudo pronto para, se eu tiver numa situação de problema, já resolvo lá, porque eu preciso do recurso audiovisual sempre [...].

Raquel: Mas, nem sempre tenho salas que comportem Datashow, hoje tenho meu Datashow e levo [...].

Nesse contexto, o requisito institucional de disponibilização dos trabalhos dos alunos no LMS acaba sendo cumprido com base em estratégias alternativas:

Francisco: Alguns alunos também reclamam, porque, vamos supor, por causa do projeto que a gente fez, projeto é grande, né? São dois meses de projeto, aí quando vai carregar não pode colocar as figuras, vai capenga o projeto. Entendeu? Alguns

\begin{tabular}{l|c|c|c|c|c|} 
(C) Rev. Inter. Educ. Sup. & Campinas, SP & v.4 & n.1 & p.25-51 & jan./abr. 2018 \\
\hline
\end{tabular}


alunos já trazem o $C D$ ou DVD que custa $R \$ 1,00$, eles já trazem ou, então, o pen drive e eu coloco no meu laptop, aí tem uma versão oficial e a oficiosa.

Rodrigo: Eu vou lhe confessar, eu recebi o tablet da IES campo da pesquisa e um pecado meu, eu nunca usei. Eu uso o meu próprio em sala. Mas, não peço aos alunos para usarem o deles... assim, eu também não sei te dizer se os meus alunos têm ... eu não sei se eles têm tablet.

O tablet institucional disponibilizado a alunos e professores (de alguns cursos selecionados) é uma fonte de diversos questionamentos, alguns associados ao equipamento em si, conforme a última fala mostrada acima. Outras questões parecem estar relacionadas à própria forma de manipulação dos materiais digitais, que talvez exijam um tipo de leitura à qual professores e alunos não estão acostumados, tornando o uso de material impresso mais favorável em sala, conforme se pode supor do extrato a seguir:

Virgínia: [...] no tablet quando você abre uma apostila é muito difícil você ficar indo e voltando, então no impresso [...] porque é lento, você voltar e ir, então estou observando que, mesmo os que têm tablet estão tirando cópia do impresso, em todas as minhas turmas eu observei isso.

Os usos de artefatos digitais revelados no conjunto de dados podem sugerir pouca sofisticação em termos pedagógicos, pois aludem, com frequência, a uma rotina de aquisição e reprodução de conhecimentos transmitidos. Parecem reproduzir-se as constatações de Cuban (2001) sobre a dificuldade que os professores sentem em aplicar, em suas aulas, artefatos que usam para comunicação, entretenimento e aprimoramento pessoais. Apesar das falas dos professores não indicarem, explicitamente, forte resistência ao uso das TIC, há indícios de resistência a mudança pedagógica, em parte explicáveis por contingências tais como falta de tempo e, talvez, falta de uma formação específica para a docência no ES que possibilite outras abordagens pedagógicas com o uso das TIC, visando a uma formação que ultrapasse a perspectiva meramente conteudista, contribuindo, assim, para formar sujeitos críticos e reflexivos. Em contraposição, há falas que sugerem ações de resistência pontuais aos discursos corporativos e dispositivos técnicos a eles associados, que incidem diretamente na autonomia profissional dos docentes, mas também enorme adaptabilidade e comprometimento com os alunos, o trabalho e a própria instituição.

Por outro lado, os usos empreendidos pelos alunos, pelo menos segundo os relatos dos docentes, são limitados ao acesso a informações, e não concretizam as descrições dos entusiastas sobre o potencial educacional das tecnologias digitais, incluindo possíveis benefícios pedagógicos tais como o desenvolvimento da criatividade, a colaboração e o incentivo a práticas de participação coletiva. Não obstante as dificuldades criadas por problema eventuais de infraestrutura, o cenário aqui analisado parece consistente com os achados de Henderson, Selwyn e Aston (2015) em um estudo com 1.658 alunos de duas universidades australianas: as tecnologias digitais são vistas como valiosas na organização de 
prazos e tarefas concorrentes, nas quais podem engajar-se a distância, mas têm pouca relevância em questões de ensino e aprendizagem.

\section{Concepções e preconcepções}

De uma maneira geral, os professores participantes na pesquisa se posicionam favoravelmente ao uso de artefatos digitais em sala de aula, tendo como um dos argumentos centrais a ideia que tais tecnologias possibilitam uma aproximação entre a sala de aula e o cotidiano dos alunos:

Francisco: [...] eu acho que é interessante a proposta ... não é só porque uma tecnologia nova, porque ... realmente vai tornar mais lúdico o aprendizado, o ensino, por que ... talvez vá aproximar mais daquilo que o aluno já tem no dia a dia dele. Porque ele já navega na Internet ... principalmente a interação [...].

O extrato a seguir reitera uma concepção das TIC como "arcabouço" de diferentes formas de atender as supostas necessidades dos ditos "nativos digitais" (PRENSKY, 2001), conceito que retrata jovens e crianças como proficientes, fluentes ou com domínio inato dos artefatos digitais. Demonstra, assim, uma crença nas TIC como promotoras de um tipo de "linguagem" que favorece a experiência hipoteticamente desejada pelo aluno:

César: [...] a tecnologia, ela veio para o mundo educacional, pra mim, no meu modo de ver, pra dar eficiência, mas eficiência nessa linguagem, na linguagem que ele tá procurando uma experiência diferente... e a tecnologia permite atenção multicamadas, entendeu? Multidimensão, layers $e$ formas diferentes, compartilhamento, jogo na nuvem, todo um arcabouço para isso, para servir você nisso.

A idealização dos jovens a partir de uma noção criada sem nenhum respaldo em dados empíricos - repetidamente criticada e já praticamente abandonada na pesquisa internacional (THOMAS, 2011) - obscurece questões tangíveis que efetivamente dizem respeito diretamente ao ensino, aprendizagem e à formação, de modo mais abrangente. Uma delas diz respeito à atenção e engajamento, ideias que aparecem nos relatos dos professores que questionam o problema da "distração". Os extratos a seguir apontam para essa possibilidade não apenas como uma decorrência da própria natureza do hipertexto, mas, também, como um aspecto do processo de descoberta dos alunos:

Raquel: Não, vai depender da perspectiva. Porque quando você chega realmente focado, por exemplo, em fazer uma pesquisa na Internet para determinado conteúdo, quero esses assuntos... óbvio que depois que ele achou, ele vai dar uma olhada naquele hipertexto ali e naquele ícone dali, vai andar um pouquinho, mas dai tem até a ver o que seria dispersão [...]

Virgínia: Eu notei isso quando, assim que eles ganharam o tablet, no primeiro semestre, no primeiro ano em que o tablet foi lançado, era Facebook direto.... Aí muito no Facebook... eu digo: "Olha o tablet não é para o Facebook”. Adoravam 
tirar foto com o tablet durante a aula, hoje eu já vejo que não tem muito isso, [era] mais quando era novidade, quando eles ganharam [...].

Pode-se depreender dessas falas que cabe ao professor supervisionar e manter os alunos focalizados, tarefa considerada delicada:

Artur: [...] depende muito do foco do aluno, você vai ter os dois universos. Eu acho que o universo da possibilidade da utilização, pelo perfil do alunado atual, pelo perfil dele... então a gente tem que ter um cuidado muito grande, porque pra ele estar nas redes sociais, para ele estar naquilo que talvez seja mais agradável, naquele momento para ele, é muito rápido [...].

À ideia de "distração" opõe-se a noção de "experimentação" como característica das formas do jovem atual aprender:

César: Eu discordo pelo simples motivo de que, na verdade, a linguagem ajudou a melhorar ou potencializar a linguagem do aluno. Na verdade, assim, pelo que eu compreendo, eu já fui até visitar alguns colégios, que eu tenho muita vontade de saber, como é que tá o modelo hoje de ensino desses grupos. Eu fiquei assim pasmo com a capacidade desses meninos de exigirem uma mídia que ela tenha algo que os faça experimentar, do que simplesmente uma coisa lá estática [...].

Nesse extrato, o docente revela uma forte crença na descrição generalista dos "nativos digitais": que "preferem seus gráficos antes de seu texto, ao invés do oposto (...) [,] preferem acesso aleatório (hipertexto) (...) [e] funcionam melhor conectados em rede" (PRENSKY, 2001, p. 2; tradução nossa). Entretanto, outras preocupações reveladas pelos professores sugerem que os usos das tecnologias digitais feitos por esses jovens são consistentes com a descrição de Buckingham (2011, localização 124, tradução nossa): “[...] são caracterizados não por manifestações dramáticas de inovação e criatividade, mas por formas relativamente rotineiras de comunicação e obtenção de informação". A obtenção de informação, em particular, relaciona-se a uma preocupação articulada pelos docentes, que destacam questões relativas a buscas e seleção de fontes on-line.

De forma geral, os professores concordam que o uso das TIC não favorece a diversificação de fontes utilizadas pelos alunos. Segundo os docentes, os estudantes não exploram opções e, crucialmente, utilizam fontes não confiáveis:

Lúcia: [...] os alunos acabam não diversificando as fontes de pesquisa [...].

Rodrigo: Isso é preocupante, eu tenho um... assim, nem sei... que hoje em dia Internet é complicado, né? Você tem muita coisa que não é confiável [...].

Contraditoriamente à possibilidade de fácil acesso a uma ampla gama de fontes de

n.1

p. 25-51 jan./abr. 2018 
informação, os professores relatam que, para realização de trabalhos e pesquisas escolares, os alunos se limitam ao uso de sites de busca genéricos como o Google. A fala a seguir descreve a estratégia adotada pelos alunos, que corresponde, com bastante exatidão, à estratégia de satisfycing, termo cunhado por Simon (1955, 1957 apud KENNEDY; JUDD, 2011) para descrever ações decorrentes de tomada de decisões a partir de estratégias reducionistas e parciais:

Artur: [...] eu chamei em minha sala de dicionário Google: "Vocês vão buscar no dicionário Google e tenha muito cuidado com ele”... E tem mais um problema, eles vão ao primeiro arquivo que eles encontram, eles não têm a preocupação de abrirem outros, de fazer um comparativo, não... e aí se você pega uma pesquisa vem quase tudo igual, porque eles vão ao primeiro arquivo que eles abrem. Então isso, eu percebo demais.

A fala sugere que o docente associa estratégias simplistas à ocorrência de trabalhos idênticos, ou seja, plágio. $\mathrm{O}$ extrato a seguir indica a necessidade de engajamento do docente como forma de evitar esses problemas:

Francisco: [...] cabe talvez direcionar para outras fontes e tudo mais. E não permitir só uma fonte porque, realmente, hoje em dia eu vejo assim que Internet, inclusive eles dizem o seguinte, que a Internet, como tem informação demais e a facilidade, pode levar o aluno a refletir menos.

A não-diversificação das fontes de busca pode estar associada à ideia de que há, atualmente, uma tendência ao imediatismo, a rápida obsolescência das coisas e uma demanda dos jovens por formas de aprendizagem baseadas na experiência:

César: [...] o imediatismo da tecnologia é de resolver, a tecnologia veio para resolver e acabou-se.... Rapidamente, as coisas se tornam obsoletas, sem precisar se tornar obsoletas, porque poderia durar mais um ano aí. Então, esse comportamento cultural, pra mim é o fator determinante nisso [...].

César: [...] porque assim, o que eu percebo, eles querem ... experimentar muitas coisas. Mas essa experiência não pode ser assim muito longa não, tem que ser fácil, não pode ser muito pauleira não .... Se não, ele: "Ah achei muito chato, vou fazer outra coisa”. Os jovens de hoje, que estão entrando na faculdade, já estão aí ... de tablet, já com smartphone e tudo, eles não são, eles podem até despertar para a procura da informação, mas a linguagem na qual eles foram formados é aquela de ... viver com uma experiência, deixa eu viver a experiência para eu entender o que é ... e depois de entender o que é, eu vou estabelecer um diálogo com vocêe $e$ compreender isso e te dá uma reflexão [...].

Uma possível consequência, identificada no extrato a seguir, é que os alunos acabam dando preferência à leitura de textos curtos e imagéticos, e, assim não exercitam a interpretação, pois não leem textos mais longos:

Cecília: E, assim, o que eu tenho percebido é que eles são imagéticos mesmo, eles não são capazes de ler o período, eles querem que aquele período...é assim eles vão direto e tuff. Olha e pega a mensagem como é no.... nas redes, né? Que não tem, 
assim, não tem necessidade de pensar, porque a imagem fala tudo ou então, a frasezinha já disse tudo. Quando é um texto maior no próprio Facebook, eles não leem, acham legal, mas você vê que eles curtem imagem, texto maior, que tem mais informação, eles não abrem e isso dificulta a interpretação [...].

Ao passo que identificam questões problemáticas - por exemplo, a falta de engajamento na leitura mencionada no extrato imediatamente acima - as falas relativas a características que os professores dizem identificar nos alunos tendem, como um conjunto, a simplesmente reproduzir aspectos fundamentais dos discursos hegemônicos acerca da presença da tecnologia na educação. Conforme já sugerido, o mito dos "nativos digitais" parece fundamentar as concepções de aluno que norteiam o trabalho docente, obscurecendo questões tais como a importância da dedicação, do esforço e da atenção mesmo em situações de aprendizagem que possam ser descritas como "lúdicas".

Conceitos como o de "nativos digitais" são consistentes com os discursos que descrevem a atualidade em uma perspectiva determinista-tecnológica, na qual a tecnologia é vista como "ferramenta" para "resolver problemas", como algo que é "essencialmente" neutro, ou seja, vazio de implicações ideológicas e políticas. Nessa perspectiva, a "inovação" se apresenta não apenas como algo desejável, mas sim como algo inescapável, conforme discutido na seção seguinte.

\section{E A INOVAÇÃO?}

As opiniões dos entrevistados sobre "inovação" são variadas, justapondo riqueza de nuances à indefinição que, de fato, caracteriza o conceito:

Raquel: Sim, mas inovação é.... é diferente, uma visão diferente para cada um.

César: eu tive professores que, simplesmente não davam aula e aí a gente pensava... eu imaginava, puxa vida, esse cara deveria trabalhar de um jeito, de outro jeito, pra gente poder pelo menos se engajar mais, né? ... Puxa, o cara poderia dar uma inovada tal, não sei o que ... tudo isso é lição.

Dário: Olha, inovar [...] eu penso o seguinte, talvez eu não seja, exatamente, um grande inovador, certo? Eu não me considero exatamente um grande inovador dentro de sala de aula. Por que eu não me considero um grande inovador de sala de aula? Porque eu não sou exatamente um pesquisador, um pedagogo, tá certo? Eu não sou um pesquisador, eu não fico ... eu não.

Esses extratos sugerem a associação de "inovação" a questões pedagógicas, não à presença de artefatos tecnológicos em sala. De fato, alguns entrevistados foram enfáticos em dizer que não inovavam em suas práticas:

Lúcia: Não, não me acho tão inovadora assim não, pelo contrário, eu me acho uma professora bem tradicional. Não tenho tanto desenvoltura nesse aspecto.... Não, não

\begin{tabular}{l|l} 
Campinas, SP & v.4
\end{tabular}

n. 1

p. $25-51$ jan./abr. 2018 
me considero, minha aula em sua maioria, ela é formal.... dou a minha aula de maneira formal, mas realmente inovação, de aplicar muitas técnicas, não.

Artur, da área das Ciências Jurídicas, classifica como "inovação" as práticas que se diferenciam do método tradicional de ensino, ou seja, da aula expositiva:

Artur: Inovo sim, por exemplo, na $<$ Disciplina $16>\ldots$ A gente tem a figura dos casos práticos no $<$ Curso $B>$.

Por outro lado, a fala de Rodrigo, que também é da área das Ciências Jurídica, apesar de sugerir dúvidas, propõe "inovação" em função da condução de "aulas dinâmicas", concebidas a partir da articulação de "conteúdo" com "situações concretas":

Rodrigo: Se eu inovo? Não sei.... Pergunta interessante. Eu procuro, olha, eu procuro fazer uma aula dinâmica, que tenha participação, para que chame atenção para uma situação concreta, uma situação real. Às vezes, pego até uma notícia que aconteceu, tal, tal, tal ... para que eles possam trazer aquilo para a contextualização, enfim conseguir absorver. (Ênfase das autoras)

A fala a seguir ilustra uma concepção de "inovação" como o uso de recursos das TIC, associando questões de linguagem e de articulação teoria-prática:

Cecília: [...] eu acho a coisa mais legal do mundo se tivesse aquele... jogos... que eles pudessem fazer .... Pegava o tablet deles ali ou pegava lá na Internet, fazia do conteúdo .... Vamos lá, vamos fazer, esse, esse plano de cargos e salários. ... olha, você chegou na empresa. Ele vai andando feito um bonequinho, ai tá aqui: "Olha, fale com esse ... olhe, você passou e não deu bom dia para essa pessoa, essa pessoa ficou lá olhando" ... Uma coisa que fosse a linguagem deles, porque essa nossa linguagem... pegasse o conteúdo, né? Isso que ele precisa aprender? É. Então, vamos botar na linguagem que ele entende, sabe? Tinha que ter isso.

Nessa perspectiva, seria concebível que a "inovação" nas práticas fosse naturalmente concretizada por professores atuantes na área da Computação, mas a fala a seguir, de um professor atuante nesta área, sugere um posicionamento diferente:

Eduardo: Eu não considero mais inovação, o que eu faço ... eu acho que fujo do padrão, mas eu acho que eu não inovo. Eu não sei nem se isso está correto essa afirmação ... porque, assim, nós docentes, a gente é muito avesso, à exceção [é] o pessoal de tecnologia, mas é muito avesso a inovar. Se bem que, eu posso exemplificar ... não, mas eu não considero inovação ... enfim, não sei direito .... Uma grande maioria do que seria inovação para os demais, já é o nosso dia a dia. Por isso que eu digo, pra gente não é inovação, porque faz parte do nosso dia a dia. Mas, esse lag, esse hiato que existe aqui, pra maioria dos docentes das outras disciplinas é um quebra de paradigma muito grande.

Quando "inovação" é vista como algo integral ao fazer pedagógico na área da Computação, reitera-se a associação do "inovar" com a ação de "utilizar tecnologias", que fundamenta as 
concepções que circulam amplamente na instituição. Porém, dificuldades em inovar dessa forma podem ser justificadas em função de problemas de infraestrutura institucional:

Francisco: Sei não, poderia ser mais, vamos supor agora essa tecnologia aí... algumas vezes, também eu sinto falta da rede. Algumas vezes, eu procurei inovar e o ambiente não permite, faltavam algumas... eu preparei as aulas, né? Pra poder usar a Internet, como professor se não tem rede, se o acesso é lento, essas coisas, então... Algumas tentativas de inovação foram... não avançaram porque hoje eu dia, a gente precisa de redes de computadores [...].

"Inovar" pode, também, significar adaptar-se às circunstâncias da aula, conforme a turma, o conteúdo, o tempo disponível. O aluno, nessa concepção, ajuda a definir o ritmo da aula, de modo que "inovar" seria não se fixar os percursos da aula a priori.

César: Eu acho que sim, todo dia, porque eu não deixo a aula... eu tenho um script da aula, mas a única coisa que eu sei do meu script é onde eu quero chegar, os caminhos que eu vou levando, eu vou junto com a turma. Eu acho que isso, todo professor, na hora de montar o seu conteúdo, precisa entender. Ele não tem mais que começar no quadro aqui e terminar ali, não existe essa linguagem mais, não existe [...].

Lígia: Durante a aula sim... eu não faço isso durante meu planejamento, o meu planejamento é sempre igual, só que durante a fala, na aula, que eu percebo que naquela turma tem um cara mais experto ${ }^{3}$ eu já me lembro da história, já conversei com ele... aí, eu procuro trazer aquela realidade dele para cá.. Se eu vejo que na turma tem um cara que é o inverso ... eu procuro trazer uma analogia, acaba que a aula, ela é sempre alterada, em relação ao que eu planejei, como é uma mesma disciplina para turmas diferentes, só no momento da aula que eu percebo.

O depoimento de Cecília relaciona "inovação" com certa flexibilidade para se comunicar com o perfil de aluno contemporâneo. Nesse sentido, ela reclama por novas práticas no modo de se comunicar com o aluno, diferentes da aula expositiva:

Cecília: Eu sou muito preocupada e já tive até discussões com colegas aqui que acham diferente. Mas eu penso assim, o aluno mudou mesmo, o tipo de aluno mudou, não é como eu, você, não é como nossas mães, não. Esse nosso aluno independente daqui da outra IES, até da pós, tem outro tipo de postura, toda a formação. Eu queria, eu quero novas práticas ... inovar na maneira de comunicar com eles, não aquela história da gente ficar só falando [...].

Como um exemplo de inovação em sala, Raquel descreve uma estratégia com um viés criativo que, segundo ela surpreendeu os alunos:

Raquel: Mas, por exemplo, inovo quando, de repente, eles estão esperando um texto jurídico em sala de aula e eu chego com um Guimarães Rosa e ali, do Guimarães

\footnotetext{
${ }^{3}$ Jargão utilizado na área da Computação, derivado do termo inglês expert, ou seja, especialista.
} 
Rosa a gente acaba discutindo algo relacionado, dentro do âmbito jurídico. Outra, eu fiz agora a pouco um debate sobre.... Aliás, eu fiz um júri simulado em cima de cordéis, dividi a sala em 4 equipes, uma ficou para defender outra para acusar [...].

Dário, por sua vez, parece relacionar, necessariamente, o uso da tecnologia em sala com uma abordagem pedagógica. Ele vê as TIC como coadjuvantes no processo ensino-aprendizagem, não como fim e, sim, como meio. O professor concebe a pesquisa de novas tecnologias para a sala de aula (aparentemente, no sentido de conhecimento científico) e a pesquisa de novas formas de dar aula (num sentido de criar métodos que usem as tecnologias) como tarefas exclusivas dos pesquisadores da área da Educação:

Dário: [...] a tecnologia não é para ganhar o Oscar de melhor ator, a não ser na empresa que venda tecnologia. Também, eu uso a tecnologia em sala de aula, como meio... eu não fico pesquisando novas tecnologias, novas formas de dar uma aula, não, não, não.

Duas concepções gerais sobre "inovação" emergiram da análise das falas dos professores. Na primeira, a "inovação" associa-se a práticas pedagógicas, e pode ser descrita como qualquer abordagem diferente do que seja considerado o método "tradicional" de ensino, ou seja, a aula expositiva. Um aspecto central nessa concepção é que as práticas ditas "inovadoras" colocam o aluno como sujeito ativo no processo de ensino e de aprendizagem. Na segunda concepção, "inovação" está irremediavelmente associada ao uso rotineiro de artefatos digitais. Assim, constata-se que as perspectivas sugeridas pelos professores se alinham fortemente com aquelas construídas e disseminadas institucionalmente. É, também, revelador que a maioria dos professores concorda em um aspecto particular: que usar as TIC em sala de aula traz perspectivas favoráveis ao seu crescimento na instituição.

\section{CONSIDERAÇÕES FINAIS}

Este artigo discutiu achados de um estudo de caso que objetivou examinar concepções e práticas docentes com as TIC na ES. Em particular, focalizou resultados de uma análise de conteúdo temática de 11 entrevistas com docentes em uma IES privada.

Os achados sugerem que, apesar das claras indicações de preocupação com a didática, concretizam-se formas de "inovação" com o uso de novos artefatos para apoiar práticas previamente conduzidas e focalizadas, basicamente, na "transmissão" de conhecimento. A situação explica-se, parcialmente, por contingências como falta de tempo, carência de formação específica e o "solucionismo" que caracteriza algumas ações e demandas institucionais relacionadas às TIC. Naturalmente, os docentes se expressam muito cuidadosamente em relação a questões institucionais tais como a existência de um "modelo de ensino" centralizado e os problemas na infraestrutura. Ficam patentes, porém, os claros indícios de práticas que sugerem um forte comprometimento desses professores com seus 
alunos, com o trabalho que desenvolvem e com a própria instituição.

A perspectiva crítica adotada na pesquisa - uma perspectiva de questionamento dos discursos por mudança em uma ES dita "falida" - não significa dizer que não existam problemas nos sistemas de ES. Pelo contrário: apontam para a necessidade de desconfiar dos argumentos por mudanças que sustentam a defesa descontextualizada da "inovação", fundamentados na crença de que as TIC podem trazer uma compreensão mais profunda de conceitos complexos e preparar, assim, os estudantes para ambientes de trabalho futuro e, teoricamente, pouco previsíveis. Os achados aqui apresentados sugerem que, na melhor das hipóteses, tem havido um impacto bem modesto das TIC nas estratégias de ensino comumente utilizadas, uma vez que a integração de novos artefatos parece ser feita de modo a possibilitar a continuidade de práticas pedagógicas já estabelecidas. Apesar das falas dos professores não indicarem, explicitamente, forte resistência ao uso das TIC, contém indícios de resistência a mudança pedagógica, em parte explicáveis por contingências tais como falta de tempo e, talvez, falta de uma formação específica para a docência no ES que desenvolva sujeitos críticos e reflexivos.

Por outro lado, as falas representam ações de resistência pontuais aos discursos e dispositivos técnicos corporativistas, que incidem diretamente na autonomia profissional dos professores, e contém indicações de ações que demonstram tentativas de ensinar para a compreensão e desenvolvimento dos alunos, para além da simples transmissão de conhecimentos. Assim, destacam-se questões mais sutis da relação entre as TIC e as práticas docentes na ES que são obscurecidas pelos discursos generalistas e essencialmente doutrinários predominantes na área, discursos marcados por um maniqueísmo que opõe, de maneira simplista, "resistência" a "adesão" às TIC. Ficam claras, também, a enorme adaptabilidade e dedicação dos professores ao fazer docente, o que reitera a necessidade de estudos empíricos e localizados que desafiem discursos generalistas e, principalmente, a culpabilização do professor.

\section{REFERÊNCIAS}

ALTBACH, Phillip; REISBERG, Liz; RUMBLEY, Laura. Trends in Global Higher Education: Tracking an Academic Revolution. A Report for the World Conference on Higher Education. Paris: UNESCO, 2009.

\section{BARDIN, Laurence. Análise de conteúdo. Lisboa: Edições 70, 1977.}

BRASIL. Decreto n. 2306, de 19 de agosto de 1997. Regulamenta, para o Sistema Federal de Ensino[...], e dá outras providências. Coleção de Leis do Brasil, v. 8, p. 5.287, 1997. Disponível em: < http://www2.camara.leg.br/legin/fed/decret/1997/decreto-2306-19-agosto1997-437195-publicacaooriginal-1-pe.html >. Acesso em: 22 set. 2017. 
BUCKINGHAM. David. Preface. In: THOMAS, M. (Org.) Deconstructing Digital Natives. Edição para Kindle. Londres: Routledge, 2011.

CASTELLS, Manuel. A Sociedade em Rede. 3.ed. São Paulo: Paz e Terra, 2000.

COHEN, Louis; MANION, Lawrence; MORRISON, Keith. Research Methods in Education. 5 ${ }^{\mathrm{a}}$ ed. Londres: Routledge, 2007.

CUBAN, Larry. Oversold and underused: computers in the classroom. Harvard University Press: Cambridge; Londres, 2001.

CUNHA, Maria Isabel. Qualidade da graduação: a relação ensino, pesquisa e extensão e o desenvolvimento profissional docente. Araraquara, SP: Junqueira \& Marin, 2012.

FERREIRA, Giselle Martins dos Santos; ROSADO, Luiz Alexandre da Silva; CARVALHO, Jaciara de Sá. Resistência Híbrida. In: FERREIRA, G. M. S.; ROSADO, L. A. S.; CARVALHO, J. S. (Org.) Educação e tecnologia: abordagens críticas. Rio de Janeiro: Editora UNESA, 2017, p. 6-10. Disponível em < https://ticpe.files.wordpress.com/2017/04/ebook-ticpe-2017.pdf>. Acesso em: 22 set. 2017.

FERREIRA, Giselle Martins dos Santos; MOREIRA, Laélia Carmelita Portela. Qualidade na Educação Superior: reflexões sobre um trabalho de tradução. Postagem no blog Diálogos sobre TIC e Educação. Rio de Janeiro: Programa de Pós-Graduação em Educação da Universidade Estácio de Sá, 4 dez. 2014. Disponível em: < https://ticpe.wordpress.com/2014/12/04/qualidade-na-educacao-superior-reflexoes-sobre-umtrabalho-de-traducao/ >. Acesso em: 22 set. 2017.

FERSTER, Bill. Teaching Machines. Edição para Kindle. Baltimore: John Hopkins University Press, 2014.

FREITAS, Rejane Cunha; FERREIRA, Giselle Martins dos Santos. As Tecnologias de Informação e Comunicação no Ensino Superior: usos por docentes. In: PEDRO, N.; PEDRO, A.; MATOS, J. F. PIEDADE, J.; FONTE, M. (Org.). Digital Technologies and Future School. 1ed. Lisboa: Universidade de Lisboa, 2016, p. 648-661.

HARVEY, Lee; WILLIAMS, James. Fifteen years of Quality in Higher Education. Quality in Higher Education, v. 16, n. 1, p. 3-36, 2010.

HENDERSON, Michael; SELWYN, Neil; ASTON, Rachel. What works e why? Student perceptions of 'useful' digital technology in university teaching learning. Studies in Higher Education, p. 1567-1679, 2015. DOI: 10.1080/03075079.2015.1007946. Disponível em: < https://www.academia.edu/12018196/What_works_and_why_Student_perceptions_of_useful _digi-tal_technology_in_university_teaching_and_learning >. Acesso em 22 set. 2017. 
KAZAMIAS, Andreas. O conhecimento educacional: um tema negligenciado na educação comparada. In: COWEN, R; KAZAMIAS, A. M.; ULTERHALTER, E. (Org.). Educação comparada: panorama internacional e perspectivas. Volume 2. Brasília: UNESCO / CAPES, 2012, p. 193-204.

KENNEDY, Gregor; JUDD, Terry. Beyond Google and the "satisficing" searches of digital natives. THOMAS, M. (Org.) Deconstructing Digital Natives. Edição para Kindle. Capítulo 8. Londres: Routledge, 2011.

KENSKI, Vani. Tecnologia educacional: uma nova cultura de ensino e aprendizagem na universidade. In: SPELLER, P., ROBL, F.; MENEGHEL, S. M. (Org.). Desafios e perspectivas da educação superior brasileira para próxima década. 2011-2020. Brasília: UNESCO / CNE-MEC, 2012. p. 110-126. Disponível em: < http://unesdoc.unesco.org/images/0021/002189/218964POR.pdf >. Acesso em: 22 set. 2017.

MASETTO, Marcos Tarcísio. Inovação na Educação Superior. Interface - Educação, Saúde e Comunicação, v. 8, n. 14, p.197-202, 2004. Disponível em:

< http://www.scielo.br/pdf/icse/v8n14/v8n14a17.pdf >. Acesso em: 15 ago. 2017.

ORGANIZAÇÃO DE COOPERAÇÃO E DESENVOLVIMENTO ECONÔMICOS (OCDE). Education at a Glance 2012: OECD Indicators. 2012. Disponível em: < http://www.oecd.org/edu/EAG\%202012_e-book_EN_200912.pdf >. Acesso em: 22 set. 2017.

PRENSKY, Mark. Digital natives, digital immigrants. On the Horizon, v. 9, n. 5, p. 1-6, 2001a. Disponível em: < https://www.marcprensky.com/writing/Prensky\%20\%20Digital\%20Natives, \%20Digital\%20Immigrants\%20-\%20Part1.pdf >. Acesso em: 22 set. 2017.

ROSADO, Luiz Alexandre da Silva; FERREIRA, Giselle Martins dos Santos; CARVALHO, Jaciara de Sá Educação e Tecnologia na literatura acadêmica on-line em português. In: FERREIRA, Giselle Martins dos Santos; ROSADO, Luiz Alexandre da Silva; CARVALHO, Jaciara de Sá (Org.) Educação e tecnologia: abordagens críticas. Rio de Janeiro: Editora UNESA, 2017, p. 208-254. Disponível em < https://ticpe.files.wordpress.com/2017/04/ebook-ticpe-2017.pdf>: Acesso em: 22 set. 2017.

SAMPAIO, Helena. O setor privado de ensino superior no Brasil: continuidades e transformações. Revista Ensino Superior Unicamp. Campinas, p. 28-43, 2011. Disponível em: < http://www.revistaensinosuperior.gr.unicamp.br/edicoes/ed04_outubro2011/05_ ARTIGO_PRINCIPAL.pdf >. Acesso em: 22 set. 2017.

SELWYN, Neil. Educação e Tecnologia: questões críticas. Trad. Giselle M. S. Ferreira. In: FERREIRA, G. M. S.; ROSADO, L. A. S.; CARVALHO, J. S. (Org.) Educação e tecnologia: abordagens críticas. Rio de Janeiro: Editora UNESA, 2017, p. 85-103. Disponível em < https://ticpe.files.wordpress.com/2017/04/ebook-ticpe-2017.pdf >: Acesso em: 22 set. 2017.

\begin{tabular}{|l|c|c|c|c|c|}
\hline (C) Rev. Inter. Educ. Sup. & Campinas, SP & v.4 & n.1 & p.25-51 & jan./abr. 2018 \\
\hline
\end{tabular}


SELWYN, Neil. Em defesa da diferença digital: uma abordagem crítica sobre os desafios curriculares da Web 2.0. 2011. Disponível em: < https://www.academia.edu/4098764/En_defesa_da_diferenca_digtal_uma_abordagem_critica_sobre_os_desafios_curriculares_da_web_2.0 >. Acesso em: 22 set. 2017.

THOMAS, Michael. (Org.) Deconstructing Digital Natives. Edição para Kindle. Londres: Routledge, 2011.

\section{${ }^{\mathrm{i}}$ Sobre os autores}

\section{Giselle Martins dos Santos Ferreira}

E-mail: gmdsferreira@gmail.com / ORCID: http://orcid.org/0000-0002-8498-5390

Universidade Estácio de Sá - Brasil

Pós-Doutorado em Educação pela Open University do Reino Unido [UKOU].

Rejane Cunha Freitas

E-mail: rejanecunhafreitas@ gmail.com / ORCID: http://orcid.org/0000-0002-6907-5954

Centro Universitário Estácio do Ceará - Brasil

Doutorado em Educação pela Universidade Estácio de Sá [UNESA].

\section{Laélia Carmelita Portela Moreira}

E-mail: moreira.laelia@gmail.com / ORCID: http://orcid.org/0000-0003-2286-0530

Universidade Estácio de Sá - Brasil

Doutorado em Educação pela Universidade Federal do Rio de Janeiro [UFRJ]. 